\title{
Infraclavicular Block for Elbow Surgery in Quadriplegic Patient with Previous History of Autonomic Dysrreflexia
}

\author{
García Ramón J., Carrión García JL., Boix Tundidor E. \\ Servicio de Anestesiología. Hospital Arnau de Vilanova-Lliria. Valencia, Spain
}

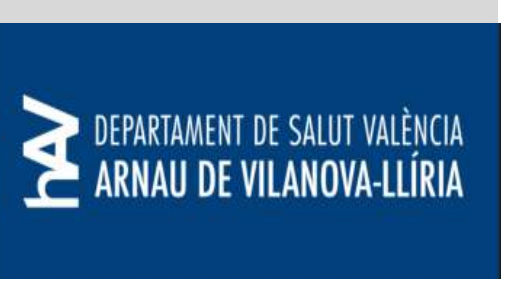

\section{Introduction}

Autonomic dysrreflexia (AD) is a potentially dangerous (even life-threatening) syndrome consisting of uncontrolled hypertension (along with flushing, piloerection, sweating) due to imbalanced reflex sympathetic discharge that develops in patients with chronic spine injury higher than T6 in relationship with painful stimuli and hollow viscus distension.

\section{Case report}

A 58 year old quadriplegic patient presented for elbow surgery due to olecranon fracture. His past medical history was significant for complete C5-C6 quadriplegia (ASIA A). He was using BiPAP for 7-8h/day (shortness of breath when speaking out loud) and baclofen for spasticity He had undergone previous urologic surgery and surgical scarotomies in which he had suffered from episodes of $A D$ as well as spontaneous episodes related to full bladder or

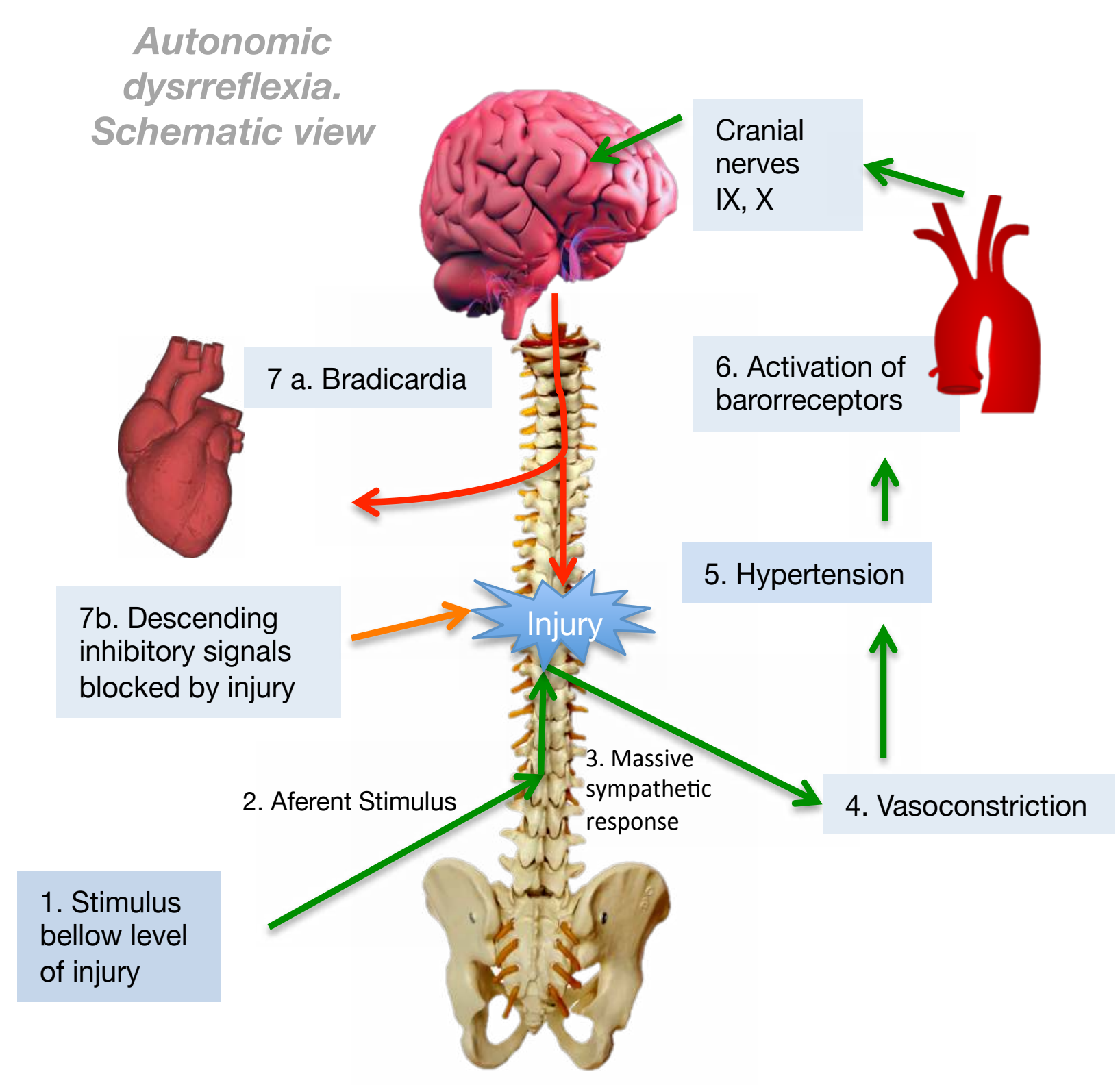
rectum.

We placed an US guided infraclavicular (IC) block with $15 \mathrm{ml}$ of 0 ' $5 \%$ levobupivacaine for surgery as a diaphragm sparing brachial plexus block in order to prevent $A D$ and respiratory failure. Upper limb spasticity made impossible an axillary approach. US scanning showed a rare disposition of the plexus at IC location with cords running together in a cluster. The patient did not receive any sedation following his preference. Surgery was carried out uneventfully and the patient was discharged to the PACU where lung US was performed ruling out phrenic palsy.

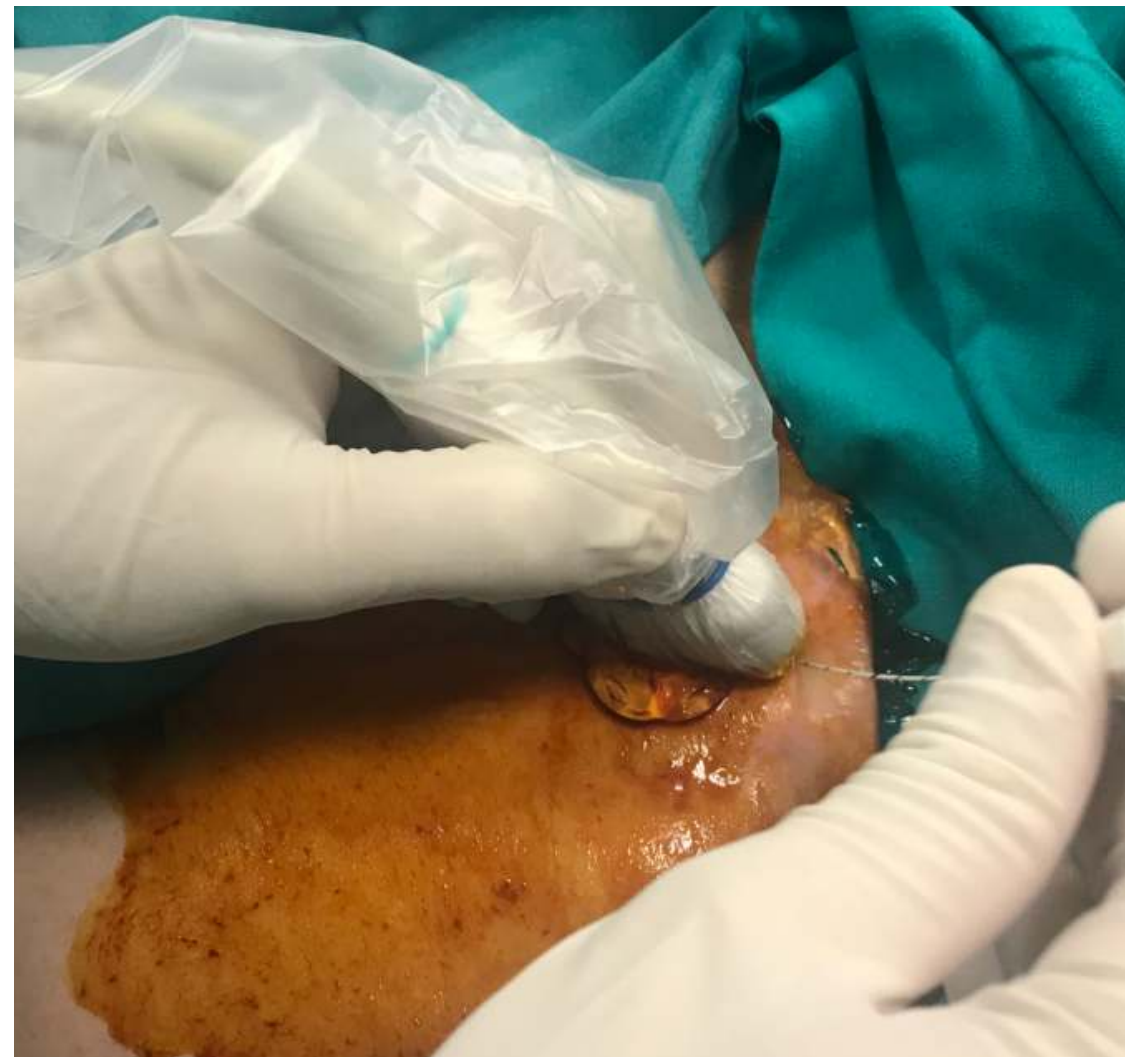

1. Probe placement and needle

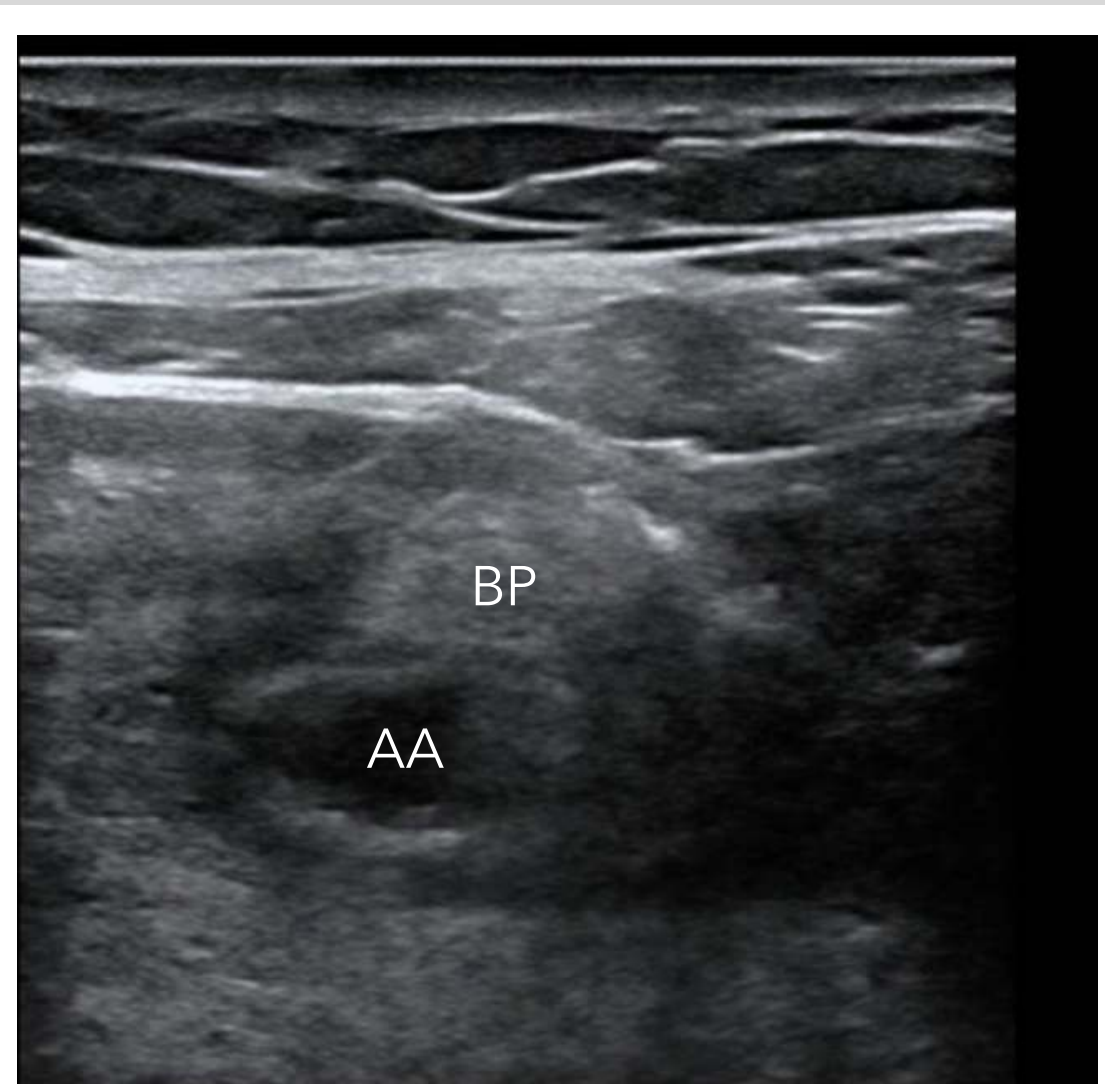

2. US image showing brachial plexus (BP) at IC location with cluster distribution. LA surrounding the axillary artery (AA)

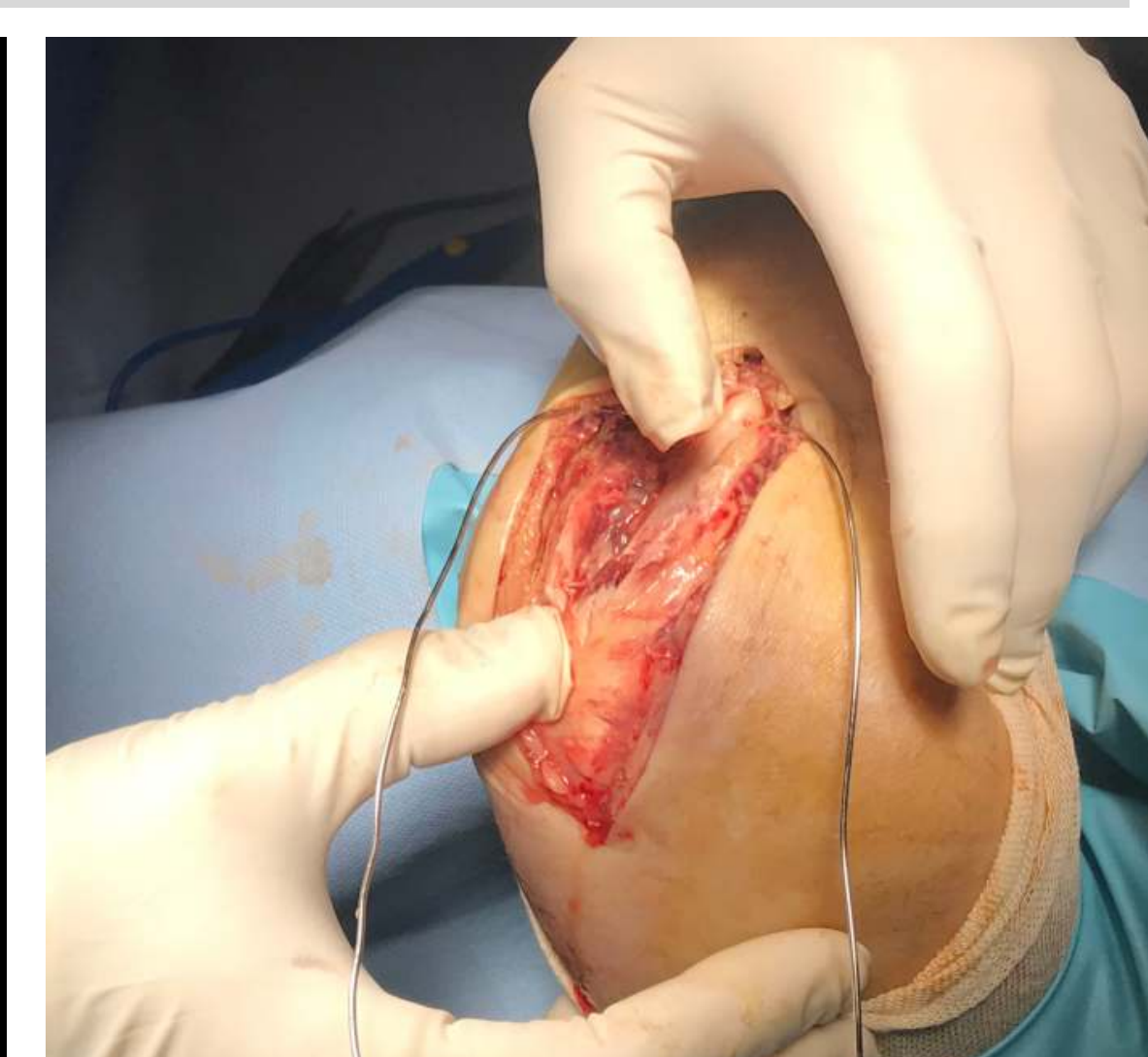

3. Surgical exposure of fracture

\section{Discussion}

Infraclavicular approach to brachial plexus could be a safe alternative for quadriplegic patients presenting for upper limb surgery to prevent AD. Among its advantages we should consider its diaphragm sparing potential. We performed the IC block because of the previous episodes of AD suffered by the patient which had been life-threatening. IC block should be considered as an alternative in high risk quadriplegic patients undergoing upper limb surgery.

1. Habibi A., Schmeising C., Gerancher JC.. Interscalene Regional Anesthesia in the prevention of Autonomic Dysrreflexia in Quadriplegic Patient Undergoing Shoulder Surgery. Anesthesia Analgesia 1998; 88:98-9.

2. Greene ES, Seltzer JL. Autonomic Dysrreflexia during upper extremity surgery. Can Anaesth Soc J 1981;28:268-71

3. Wan D, Krassioukov AV. Life-Threatening Outcomes Associated with Autonomic Dysrreflexia: A Clinical Review. J Spinal Cord 